\title{
Erratum to: Crystallization kinetics of polyamide 11 in the presence of sepiolite and montmorillonite nanofillers
}

\author{
Katalee Jariyavidyanont ${ }^{1} \cdot$ Walter Focke ${ }^{2} \cdot$ René Androsch $^{1}$
}

Published online: 22 June 2016

(C) Springer-Verlag Berlin Heidelberg 2016

Erratum to: Colloid Polym Sci (2016) 294:1143-1151

DOI 10.1007/s00396-016-3874-y

The original version of this paper contained an error.

The first sentence in the "Materials and preparation" subsection under "Experimental" section should be changed.

From:

"In this study, a high-viscosity, natural PA 11 extrusion grade Rilsan BESNO TL from Atofina with a melting volume index of $1 \mathrm{~cm}^{3}(10 \mathrm{~min})^{-1}\left(235^{\circ} \mathrm{C}, 2.16 \mathrm{kp}\right)$ was used [1]."

To:

"In this study, high-viscosity extrusion-grade PA 11 Rilsan from Atofina was used [1]. It contained BBSA plasticizer, with its amount of less than $7.5 \%$ controlled by blending neat (BESNO TL) and plasticizer-containing (BESNO P20 TL) grades."

The online version of the original article can be found at http://dx.doi. org/10.1007/s00396-016-3874-y.

\section{René Androsch}

rene.androsch@iw.uni-halle.de

1 Center of Engineering Sciences, Martin Luther University Halle-Wittenberg, 06099 Halle/Saale, Germany

2 Department of Chemical Engineering, Institute of Applied Materials, University of Pretoria, Private Bag X20, Hatfield,

0028 Pretoria, South Africa 